PRESENTACION

ALFREDO A. ROGGIANO: Éste nimero......................... 603

NOTA PRELIMINAR

JULIO ORTEGA: La literatura mexicana y la experiencia comunitaria

605

\title{
I. ENTREVISTAS
}

MANUEL ULACIA: Pocsia, pintura, música, etcétera. Conversación

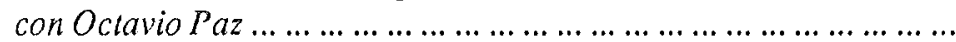

JULIO ORTEGA: Carlos Fuentes: para recuperar la tradición de $L a$

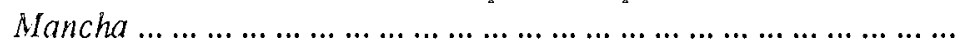

MARIO MAGALLON: Leopoldo Zea. La filosofía latinoamericana: una forma de expresión propia ... ................................ ....

EMMANUEL CARBALLO: José Luis Marlinez: se puede ser en Jalisco "profeta en su tierra" .....................................

ELIANA ALBALA: Juan José Arreola: fragmentos para el rompecabezas de un mundo que se perdió como las piedras ... ... ...........

LADY ROJAS-TREMPE: Elena Garro dialoga sobre su tealro con Guillermo Schmidhuber .......................................

II. FONDO HISTORICO-CULTURAL 
CARLOS MONSIVAIS: No con un sollozo, sino entre disparos (notas sobre cultura mexicana 1910-1968) ...............................

GABRIELLA DE BEER: El Ateneo y los ateneístas: un examen retrospectivo ... ............................................ .... SERGE I. ZAITZEFF: IIacia el concepto de una generación perdida

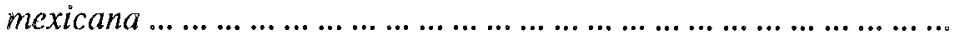

III. DOS PANORAMAS

MARGARITA PEÑA: Literatura femenina en México en la antesala del año 2000 (anlecedentes siglos $X I X$ y XX) ........................

LAURO ZAVALA A.: El nuevo cuento mexicano, 1979-1988 ... ... ...

\section{ALFONSO REYES}

GEORGE D. SCHADE: Dos mexicanos vistos por si mismos: Reyes y Abreu Gómez ... ..............................................

ROBERTO HOZVEN: Sobre la "inteligencia americana" de Alfonso Reyes ................................................... ...

JAMES WILLISROBB: Alfonso Reyesen busca de la unidad (constan-

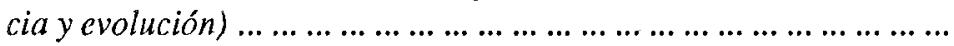

\section{NARRATIVA}

FELIPE GARRIDO: ¿Revolución en las letras? ......................

SILVIA LORENTE MURPHY: La Revolución Mexicana en la novela

LUIS LEAL: Mariano Azuela: precursor de los nuevos novelistas ...

MARGO GLANTZ: La Novela de la Revolución Mexicana y la sombra del caudillo .................................................. ...

EDITH NEGRIN: El narrador José Revueltas, la tierra y la historia ...

DIDIER JAEN: La Victoria de Samotracia en Al filo del agua de Agustín Yáñez .................................................

DAVID BARY: Poesia y narración en cuatro novelas mexicanas ...... CHRISTOPHER DOMINGUEZ-MICHAEL: Nolas sobre mitos nacionales y novela mexicana $(1955-1985)$... ...................... 
NORMA KLAHN: Un nuevo verismo: apuntes sobre la última novela mexicana ...................................................

YVETTE JIMENEZ DE BAEZ: $J$ uan Rulfo. De la escritura al sentido SERGIO FERNANDEZ: "Pedro Páramo:" Una sesión espiritista ... MARTHA L. CANFIELD: Dos enfoques de "Pedro Páramo": una

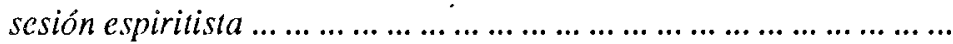

GUSTAVO C. FARES: Juan Rulfo: crítica reciente .....................

MONIQUE LEMAITRE: El deseo de la muerte y la muerte del deseo en la obra de Elena Garro. Ilacia una definición de la escritura en

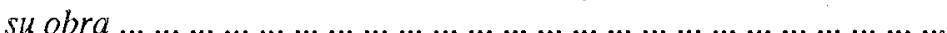

SARA POOT-HERRERA: "La feria", una crónica pueblerina .......... JORGE RODRIGUEZ-PADRON: La original narrativa de Arturo Azuela

FEDERICOCAMPBELL: Ibargüengoitia: la sátira histórico-política

\section{POESIA}

HUGO MENDEZ RAMIREZ: La afinidad poética de Lugones y Tablada

BEATRIZ ESPEJO: Ramón López Velarde, un pesimista lujurioso ...

SAMUEL GORDON: Modernidad y vanguardia en la literatura mexicana: estridentistas y contemporáneos....

MANUEL MARTIN-RODRIGUEZ: El fondo angustiado de los "noc"urnos" de Xavier Villaurrutia

BEATRIZ GARZA-CUARON: Claridad y complejidad en "Muerte sinfin", de José Gorostiza

MANUEL DURAN: Las revistas"Taller" y "Tierra Nueva", nueva generación, nuevas inquietudes ...................................

FRANK DAUSTER: Poetas mexicanos nacidos en las décadas de 1920,1930 y 1940

PAUL W. BORGESON,JR: La espiga amotinada y la poesía mexicana HUGO VERANI: Octavio Paz, primeras letras, 1941-1943 ... ......... RAFAEL VARGAS: Nuevas voces de la poesía mexicana: seis casos

JUAN MALPARTIDA: Tres poetas mexicanos (Ulacia, Mendiola,

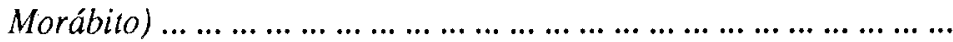


VII. TEATRO

GUILLERMO SCHMIDHUBER: Díptico sobre el teatro mexicano de los treinta: Bustillo y Magdaleno, Usigli y Villaurrutia .............. 1221 OSCAR RIVERA-RODAS: Para una semiótica proxémica en Villa-

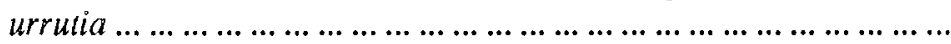

MABEL MORAÑA: IIistoricismo y legitimación del poder en "El gesticulador" de Rodolfo Usigli ........................................... ARTURO RAMIREZ JUAREZ: Dos décadas de la dramaturgia

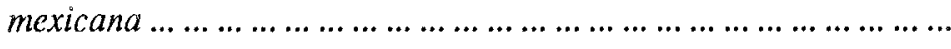

